\title{
Autism and classification systems: a study of 84 children
}

Matteo Chiappedi ${ }^{1,2^{*}}$, Giorgio Rossi ${ }^{3}$, Maura Rossi ${ }^{2}$, Maurizio Bejor ${ }^{1,4}$, Umberto Balottin ${ }^{2,3}$

\begin{abstract}
Background: A number of studies have shown that current classification systems (ICD 10, DSM IV TR) have limitation when applied to autistic children and the category PDD NOS (DSM IV TR) has in particular been criticized. To check the possible usefulness of other classification systems to better describe patient's functioning, we retrospectively studied 84 patients, seen consecutively in our Child Neurology and Psychiatry Department (excluding only those presenting for another disease even if with clinical signs of a PDD).

Methods: We tried to classify them according to ICD 10, DSM IV TR, CFTMEA-R, "operational classification" (Manzano and Palacio) and de Ajuriaguerra's classification.

Results: We found a good correspondence between DSM IV TR and ICD 10 and the use of psychodynamic classification systems (in particular CFTMEA-R) was useful to differentiate clinical subtypes collected under the PDD NOS etiquette according to DSM IV TR.

Conclusions: To rationalize research efforts and find better tailored therapies, we need to improve PDD classification systems, using contributions coming from every field of child psychiatry and neurology: it's possible that 0-3 Classification could help this.
\end{abstract}

\section{Background}

A number of studies have shown that current classification systems (ICD 10 [1], DSM IV TR [2]) have limitations when applied to children with Autism Spectrum Disorders. According to Cohen and Volkmar [3] classification systems should aim at improving communication, through their features (internal consistency, use easiness, good definition of categories) and being widely accepted. Cantwell [4] underlines that a classification system should provide a description unifying clinical, biochemical, genetical, neurophysiological and neuroimaging findings to identify specific categories with a unique natural history, prognosis and (if possible) therapy. This system should also be logical and easy to use in clinical settings. The term Autism Spectrum Disorders comes from the theoretical work of many Authors and includes a continuum moving from the "classical" autism described by Kanner, to Asperger's syndrome, to autistic-like forms and even to autistic traits in mental retardation [5].

\footnotetext{
* Correspondence: mchiappedi@gmail.com

${ }^{1}$ Rehabilitation Unit, "Santa Maria alle Fonti" Medical Center, Don Carlo Gnocchi ONLUS Foundation, Salice Terme (PV), Italy
}

Phenomenological polymorphism and a natural course not moving towards "normality" are among the main factors which make it difficult to reach a shared classification system. After the important contributions by Rutter and Ritvo, DSM III was the first system to use the Pervasive Developmental Disorders (PDD) category, which meant to be an a-theoretical definition including children with abnormalities interesting different areas of their development. Among the criticism ([6]; [7]), Golse [8] underlined the risk to lose the importance of the emotional aspects and to focus diagnosis and therapy only on presumed (but still unclear) organic factors. Anyway a strong rational reason to accept the PDD category was the possibility to unify all "autistic-like" syndromes, previously described under various names by different authors. Moreover, specific symptoms are usually present before 30 months of age, even if they are not always seen as relevant (and reported to the pediatrician) by parents.

Current international diagnostic systems (ICD 10 and DSM IV TR) have received different criticism; among them:
C Biomed Central

(ㄷ) 2010 Chiappedi et al; licensee BioMed Central Ltd. This is an Open Access article distributed under the terms of the Creative Commons Attribution License (http://creativecommons.org/licenses/by/2.0), which permits unrestricted use, distribution, and reproduction in any medium, provided the original work is properly cited. 
- the inclusion of Rett syndrome is questioned, given its established genetical origin;

- even if ICD 10 had been projected to use criteria compatible with (at that point "soon to come") DSM IV, it provides much more detailed research criteria;

- Atypical Autism is apparently well described, but these criteria are sometimes hard to use in clinical settings;

- PDD NOS are not well defined in terms of what should be excluded from their definition;

- a dimensional vision has been hypothesized to be potentially more useful than a categorical one;

- the distinction between Childhood Autism and PDD NOS in terms of functioning is unclear;

- the lack of well defined inclusion and exclusion criteria leads to a description of PDD NOS as something totally disconnected from Childhood Autism;

- it is possible that at least some PDD NOS are the evolution of a Childhood Autism (Towbin, 1996), given that PDD NOS diagnosis is usually delayed in time probably because of the less striking behavioral features;

- current classification seem to convey the idea that PDD are the result of some organic deficit, even when this is not evident.

Other classification systems have been proposed. In our Department, we have long been familiar with three of them: CFTMEA-R [9], de Ajuriaguerra's classification [10] and Manzano and Palacio's "operational classification" [11].

We also want to quote Multiple Complex Developmental Disorder (MCDD, described by Towbin et alii [12]), in which the behavior is strikingly similar to that seen in "psychotic disharmonies".

We wanted to check the possible usefulness of other classification systems to better describe patient's functioning. We used the three psychodynamic systems which were widely used before the introduction of DSM IV in Italy (in our Department, for instance, the difference of diagnostic system used in a retrospective analysis proved to favour psychodynamic systems before 1997 and ICD or DSM IV later on $(X$ square test, $\mathrm{P}<0.0001)$ ).

\section{Patients and Methods}

We reviewed medical records of 84 children, seen in our Department of Child Neurology and Psychiatry. Inclusion criteria were:

- less than 18 year old;

- being sent with a suspected PDD without an organic disorder diagnosed or suspected;

- being sent for a complete evaluation (i.e. not for specific problems such as epilepsy).

We had performed different evaluation protocols, according to the specific patient's needs. The main diagnostic instruments were:

- anamnesis (100\% of patients);
- clinical examination (100\% of patients);

- neurological examination (100\% of patients);

- CARS (100\% of patients);

- BSE (ERC-A-III; 100\% of patients);

- development evaluation using Griffiths Mental Development Scales (59.5\% of patients, the others being non reliable);

- play observations (at least 2 session, often video recorded; $100 \%$ of patients);

- blood and urine exams (including thyroid function $(46,4 \%)$, plasma amino acids/plasma and urine organic acids (52,4\%));

- genetic testing (karyotype 100\%, Fragile X testing $51.2 \%)$

- EEG (67.9\%);

- evoked potentials (Visual Evoked Potentials and Brainstem Auditory Evoked Potentials, 71.4\%);

- MRI (54.8\%) or CT (34.5\%) or both $(4.8 \%)$.

We reviewed all available data in order to classify patients according to different systems:

- DSM IV TR;

- ICD 10;

- CFTMEA-R;

- Manzano and Palacio's "operational classification"

- De Ajuriaguerra's classification.

Due to space limitations, we will summarize here only the most important data in the anamnesis of our patients. They were mainly males (84.5\%), and about half of them (52.8\%) had been seen before 48 months of age (but $77.4 \%$ had been first seen by a specialist by the age of three). We tried to excluded, as described, patients sent to our Centre for a specific organic disorder; still one of our patients, sent with a provisional diagnosis of "idiopathic autism", was found to be affected by Sclerosis Tuberosa after brain MRI showed almost specific lesions.

Speech delay or absence was the most commonly reported reason to consult a specialist $(82.1 \%)$, followed by non specified "relational difficulties" (56\%), behavioral problems (46.4\%), sleeping disturbances (22.6\%), a global developmental delay $(16.1 \%)$ or feeding disturbances (6.0\%); $90.5 \%$ of patients presented three or less of these symptoms.

We found $46.4 \%$ of patients with neurological "soft signs"; $84.5 \%$ being isolated at least "quite often"; 70.2\% with stereotyped behavior; $86 \%$ with a development delay (among those we could reliably evaluate); no specific internal medicine abnormalities; 47.4\% EEG abnormalities; $15 \%$ brainstem auditory evoked potential alterations; $12.1 \%$ visual evoked potential alterations; $11.7 \%$ specific neuroradiological abnormalities (29.9\% non specific).

\section{Results}

We found a good correspondence between DSM IV TR and ICD 10 (about 1/3 of our patients being diagnosed 
as Childhood Autism or Autistic Disorder and 2/3 PDD NOS or Atypical Autism). Considering that PDD NOS should be a residual category, the number of patients receiving this diagnosis is obviously much higher than expected.

The diagnosis according to the different systems used is shown in details in Table 1 and 2. For CFTMEA-R and "operational classification" (Manzano and Palacio) only diagnostic categories attributed to at least one of our patients are shown. We were not able to classify 3 of our patients according to the "operational classification" (Manzano and Palacio), because we missed some important and specific information.

\section{Discussion}

We found a good level of homogeneity (76.7\%) among patients with a diagnosis of Autistic Disorder (according to DSM IV TR criteria) or Childhood Autism (according to ICD 10). They generally resemble Kanner's historical description of autistic children, even if a few less typical clinical pictures are included. The latters have more symptoms on all three core Autism Spectrum Disorders domains compared to those with Pervasive Developmental Disorders Not Otherwise Specified (PDD NOS), exactly as reported in current scientific literature [13].

In contrast, in the PDD NOS group (according to DSM IV TR, but superimposable to Atypical Autism group according to ICD 10) we found a low level of homogeneity (5.6\%). However, the use of psychodynamic classification systems (in particular CFTMEA-R) allowed to differentiate different clinical subtypes collected under the PDD NOS etiquette according to DSM IV TR (or Atypical Autism according to ICD 10). Putting together the psychodynamic classification systems, we

Table 1 Patients with Autistic Disorder (DSM IV TR criteria) classified according to CFTMEA-R, Manzano-Palacio "operational classification" and De Ajuriaguerra's classification

\begin{tabular}{|c|c|c|c|}
\hline PATIENT & CFTMEA-R & Manzano-Palacio & De Ajuriaguerra \\
\hline 1 & Kanner's Autism & Primary Autism & Kanner's early autistic psychosis \\
\hline 2 & Kanner's Autism & Primary Autism & Kanner's early autistic psychosis \\
\hline 3 & Kanner's Autism & Primary Autism & Kanner's early autistic psychosis \\
\hline 4 & Kanner's Autism & Primary Autism & Kanner's early autistic psychosis \\
\hline 5 & Kanner's Autism & Primary Autism & Kanner's early autistic psychosis \\
\hline 6 & Kanner's Autism & Primary Autism & Kanner's early autistic psychosis \\
\hline 7 & Kanner's Autism & Primary Autism & Kanner's early autistic psychosis \\
\hline 8 & Kanner's Autism & Primary Autism & Kanner's early autistic psychosis \\
\hline 9 & Kanner's Autism & Primary Autism & Kanner's early autistic psychosis \\
\hline 10 & Kanner's Autism & Primary Autism & Kanner's early autistic psychosis \\
\hline 11 & Deficit psychosis & Deficit Psychosis & Early deficit psychosis \\
\hline 12 & Kanner's Autism & Primary Autism & Kanner's early autistic psychosis \\
\hline 13 & Other Autistic Disorders & Secondary Autism & Kanner's early autistic psychosis \\
\hline 14 & Kanner's Autism & Primary Autism & Kanner's early autistic psychosis \\
\hline 15 & Kanner's Autism & Primary Autism & Kanner's early autistic psychosis \\
\hline 16 & Other Autistic Disorders & Secondary Autism & Kanner's early autistic psychosis \\
\hline 17 & Kanner's Autism & Primary Autism & Kanner's early autistic psychosis \\
\hline 18 & Deficit psychosis & Deficit Psychosis & Early deficit psychosis \\
\hline 19 & Kanner's Autism & Primary Autism & Kanner's early autistic psychosis \\
\hline 20 & Kanner's Autism & Primary Autism & Kanner's early autistic psychosis \\
\hline 21 & Psychotic Dysarmonia & Disorganizing Psychosis & Early personality distortion \\
\hline 22 & Kanner's Autism & Primary Autism & Kanner's early autistic psychosis \\
\hline 23 & Kanner's Autism & Primary Autism & Kanner's early autistic psychosis \\
\hline 24 & Kanner's Autism & Primary Autism & Kanner's early autistic psychosis \\
\hline 25 & Kanner's Autism & Primary Autism & Kanner's early autistic psychosis \\
\hline 26 & Kanner's Autism & Primary Autism & Kanner's early autistic psychosis \\
\hline 27 & Deficit psychosis & Deficit Psychosis & Early deficit psychosis \\
\hline 28 & Kanner's Autism & Primary Autism & Kanner's early autistic psychosis \\
\hline 29 & Kanner's Autism & Primary Autism & Kanner's early autistic psychosis \\
\hline 30 & Other Autistic Disorders & Primary Autism & Early deficit psychosis \\
\hline
\end{tabular}


Table 2 Patients with Pervasive Developmental Disorder Not Otherwise Specified (DSM IV TR criteria) classified according to CFTMEA-R, Manzano-Palacio “operational classification" and De Ajuriaguerra's classification

\begin{tabular}{|c|c|c|c|}
\hline PATIENT & CFTMEA-R & Manzano-Palacio & De Ajuriaguerra \\
\hline 1 & Other Autistic Disorders & Secondary Autism & Early personality distortion \\
\hline 2 & $\begin{array}{c}\text { Childhood Schizophrenic } \\
\text { Disorders }\end{array}$ & Disorganizing Psychosis & Early personality distortion \\
\hline 3 & Deficit psychosis & Disorganizing Psychosis & Early personality distortion \\
\hline 4 & Other Autistic Disorders & Primary Autism & Early personality distortion \\
\hline 5 & Psychotic Dysarmonia & Disorganizing Psychosis & Early personality distortion \\
\hline 6 & Other Autistic Disorders & Secondary Autism & Early personality distortion \\
\hline 7 & Other Autistic Disorders & Primary Autism & Early personality distortion \\
\hline 8 & Other Autistic Disorders & Primary Autism & Early personality distortion \\
\hline 9 & Psychotic Dysarmonia & Disorganizing Psychosis & Early personality distortion \\
\hline 10 & Other Autistic Disorders & Primary Autism & Early personality distortion \\
\hline 11 & Psychotic Dysarmonia & Unable to classify & Early personality distortion \\
\hline 12 & Psychotic Dysarmonia & Symbiotic Psychosis & Early personality distortion \\
\hline 13 & Psychotic Dysarmonia & Disorganizing Psychosis & Early personality distortion \\
\hline 14 & Psychotic Dysarmonia & Disorganizing Psychosis & Early personality distortion \\
\hline 15 & Deficit psychosis & Deficit Psychosis & Early deficit psychosis \\
\hline 16 & Other Autistic Disorders & Primary Autism & Early personality distortion \\
\hline 17 & Psychotic Dysarmonia & Disorganizing Psychosis & Early personality distortion \\
\hline 18 & Psychotic Dysarmonia & Secondary Autism & Early personality distortion \\
\hline 19 & Other Autistic Disorders & Primary Autism & Early deficit psychosis \\
\hline 20 & $\begin{array}{c}\text { Childhood Schizophrenic } \\
\text { Disorders }\end{array}$ & Disorganizing Psychosis & Early personality distortion \\
\hline 21 & Kanner's Autism & Primary Autism & $\begin{array}{c}\text { Kanner's early } \\
\text { autistic psychosis }\end{array}$ \\
\hline 22 & Psychotic Dysarmonia & Secondary Autism & Early personality distortion \\
\hline 23 & Deficit psychosis & Deficit Psychosis & Early deficit psychosis \\
\hline 24 & Deficit psychosis & Deficit Psychosis & Early deficit psychosis \\
\hline 25 & Psychotic Dysarmonia & Symbiotic Psychosis & Early personality distortion \\
\hline 26 & Other Autistic Disorders & Secondary Autism & $\begin{array}{c}\text { Kanner's early } \\
\text { autistic psychosis }\end{array}$ \\
\hline 27 & Other Autistic Disorders & Primary Autism & $\begin{array}{l}\text { Kanner's early } \\
\text { autistic psychosis }\end{array}$ \\
\hline 28 & Psychotic Dysarmonia & Symbiotic Psychosis & Early personality distortion \\
\hline 29 & Deficit psychosis & Deficit Psychosis & Early personality distortion \\
\hline 30 & Kanner's Autism & Primary Autism & $\begin{array}{l}\text { Kanner's early } \\
\text { autistic psychosis }\end{array}$ \\
\hline 31 & Deficit psychosis & Deficit Psychosis & Early deficit psychosis \\
\hline 32 & Deficit psychosis & Deficit Psychosis & Early deficit psychosis \\
\hline 33 & Psychotic Dysarmonia & Disorganizing Psychosis & Early personality distortion \\
\hline 34 & Psychotic Dysarmonia & Symbiotic Psychosis & Early personality distortion \\
\hline 35 & Psychotic Dysarmonia & Unable to classify & Early personality distortion \\
\hline 36 & Other Autistic Disorders & Secondary Autism & Early personality distortion \\
\hline 37 & Other Autistic Disorders & Secondary Autism & Early personality distortion \\
\hline 38 & Other Autistic Disorders & Secondary Autism & Early personality distortion \\
\hline 39 & Other Autistic Disorders & Primary Autism & Early personality distortion \\
\hline 40 & Other Autistic Disorders & Symbiotic Psychosis & Early personality distortion \\
\hline 41 & Deficit psychosis & Deficit Psychosis & Early deficit psychosis \\
\hline 42 & Psychotic Dysarmonia & Unable to classify & Early personality distortion \\
\hline 43 & Psychotic Dysarmonia & Disorganizing Psychosis & Early personality distortion \\
\hline
\end{tabular}


Table 2 Patients with Pervasive Developmental Disorder Not Otherwise Specified (DSM IV TR criteria) classified according to CFTMEAR, Manzano-Palacio "operational classification" and De Ajuriaguerra's classification (Continued)

\begin{tabular}{cccc}
\hline 44 & Deficit psychosis & Deficit Psychosis & Early deficit psychosis \\
\hline 45 & Other Autistic Disorders & Primary Autism & Kantistic psychosis \\
\hline 46 & Other Autistic Disorders & Secondary Autism & Early personality distortion \\
\hline 47 & Other Autistic Disorders & Secondary Autism & Early personality distortion \\
\hline 48 & Deficit psychosis & Deficit Psychosis & Early deficit psychosis \\
\hline 49 & Other Autistic Disorders & Secondary Autism & Early personality distortion \\
\hline 50 & Other Autistic Disorders & Secondary Autism & Early personality distortion \\
\hline 51 & Other Autistic Disorders & Primary Autism & Early deficit psychosis \\
\hline 52 & Other Autistic Disorders & Secondary Autism & Early personality distortion \\
\hline 53 & Kanner's Autism & Primary Autism & Kanner's early \\
\hline 54 & & Primary Autism & Early personality distortion
\end{tabular}

found two main subgroups among our patients. They are defined on the basis of the prevalent symptoms: one has isolation, the hallmark of autism according to common speaking, as the main clinical feature; the other is characterized by developmental delay, which is generally early evidenced by parents. These two main factors obviously interact with each other and with many others to create the "autistic spectrum". Groups with coherent diagnosis (and clinical features) are anyway too small to draw any definite conclusion.

Some patients with PDD NOS are included in the Primary Autism or Secondary Autism groups according to Manzano and Palacio's "operational classification". This is a consequence of the different definitions used.

Our study is limited by the implicit selection of our patients (as we work in a third level centre) and their age (only $52.4 \%$ were less the 4 year old). Another relevant limitation is due to its retrospective design.

We did not use the 0-3 Classification [14] either, because it has really specific features which had only in part been explored in the medical records we used.

\section{Conclusions}

Recent scientific literature claims that to allow a systematic evaluation of existing classification systems, more comparative studies on one and the same sample of patients using different classification systems for the purposes of diagnostic codification are needed [15].

In order to rationalize research efforts and to find better tailored therapies, we need to improve autism classification systems, using contribution coming from every field of child psychiatry and neurology. Obviously this implies the ability to leave prejudices coming from all different sides. After Kandel's fundamental papers $([16,17])$, we believe it's possible and necessary to reopen (or maybe create ex novo) a constructive dialogue between different models and views in order to serve children's best interest. This is in line with the suggested need for other approaches in the definition of Autism Spectrum Disorders subtypes, such as the dimensional one [13]. We can argue that the 0-3 Classification could be an effective and acceptable model for this integration, being at the same time consistent from a psychodynamic point of view and empirically based [18].

\section{Acknowledgements}

No grants or fundings were used for this paper.

\section{Author details}

${ }^{1}$ Rehabilitation Unit, "Santa Maria alle Fonti" Medical Center, Don Carlo Gnocchi ONLUS Foundation, Salice Terme (PV), Italy. ${ }^{2}$ Department of Neurological Sciences, University of Pavia, Pavia, Italy. ${ }^{3}$ Child Neuropsychiatry Unit, IRCCS "C. Mondino" Foundation, Pavia, Italy. "Department of Surgical, Resuscitative, Rehabilitative and Transplant Sciences, University of Pavia, Pavia, Italy.

\section{Authors' contributions}

MC, GR, MR and UB participated in study design and patient's clinical assessment. MB participated in the design of the study and performed data analysis. All authors contributed to draft the manuscript, which they all read and approved in the final version.

\section{Competing interests}

The authors declare that they have no competing interests.

Received: 17 August 2009

Accepted: 29 January 2010 Published: 29 January 2010

\section{References}

1. World Health Organization: The ICD 10 classification of mental and behavioural disorders: Clinical descriptions and diagnostic guidelines Geneve, WHO Press 1992.

2. American Psychiatric Association: Diagnostic and statistical manual of mental disorders DSM IV TR Arlington VA, APA Press 2000.

3. Cohen DJ, Volkmar FR: Autismo e disturbi generalizzati dello sviluppo Trad. It. Brescia, Vannini Editrice 2005.

4. Cantwell D: Classification of child and adolescent psychopathology. J Child Psychol Psychiatry 1996, 37:3-12.

5. Balottin U, Lanzi G: L'Autismo infantile in una prospettiva storica. Giornale di Neuropsichiatria dell'Età Evolutiva 2000, 20:145-157.

6. Gillberg C: Debate and argument: Is autism a Pervasive Developmental Disorder?. J Child Psychol Psychiatry 1991, 32(7):1169-1170. 
7. Volkmar FR, Cohen DJ: Debate and argument: The utility of the term Pervasive Developmental Disorder. J Child Psychol Psychiatry 1991, 32(7):1171-1172.

8. Golse B: L'autisme infantile en France en 1994. Psychiatrie de l'enfant 1995, XXXVIII(2):463-476.

9. Mises R, Quemada N: Classification Française des Troubles Mentaux de I'Enfant et de l'Adolescent-R (CFTMEA-R) Paris, CTNERHI 2002

10. De Ajuriaguerra J: Manuel de Psychiatrie de l'Enfant II ed Trad. It. Milano, Masson 1974.

11. Manzano J, Palacio Espasa F: Studio sulla psicosi infantile Trad. It. Bologna, Zanichelli 1983.

12. Towbin KE, Dykens EM, Pearson GS, Cohen DJ: Conceptualizing "borderline syndrome of childhood" and "childhood schizophrenia" as a developmental disorder. J Am Acad Child and Adolesc Psychiatry 1999, 32(4):775-782.

13. Witwer AN, Lecavalier L: Examining the Validity of Autism Spectrum Disorders Subtypes. J Autism Dev Disord 2008, 38:1611-1624.

14. National Center for Clinical Infant Programes: Diagnostic Classification of Mental Health and Developmental Disorders of Infancy and Early Childhood, Revised (DC:0-3R) Washington DC, ZERO-TO-THREE Ed 2005.

15. Postert C, Averbeck-Holocher M, Beyer T, Muller J, Furniss T: Five Systems of Psychiatric Classification for Preschool Children: Do Differences in Validity, Usefulness and Reliability Make for Competitive or Complimentary Constellations?. Child Psychiatry Hum Dev 2009, 40:25-41.

16. Kandel ER: A new intellectual framework for psychiatry. Am J Psychiatry 1998, 155(4):457-469.

17. Kandel ER: Biology and the future of psychoanalysis: a new intellectual framework for psychiatry revisited. Am J Psychiatry 1999, 156(4):505-524.

18. Greenspan SI, Wieder S: Developmental patterns and outcomes in infants and children with disorders in relating and communicating: a chart review of 200 cases of children with autistic spectrum diagnoses. Journal of Development and Learning Disorders 1997, 1:87-141.

doi:10.1186/1824-7288-36-10

Cite this article as: Chiappedi et al:: Autism and classification systems: a study of 84 children. Italian Journal of Pediatrics 2010 36:10.

\section{Submit your next manuscript to BioMed Central and take full advantage of:}

- Convenient online submission

- Thorough peer review

- No space constraints or color figure charges

- Immediate publication on acceptance

- Inclusion in PubMed, CAS, Scopus and Google Scholar

- Research which is freely available for redistribution

Submit your manuscript at www.biomedcentral.com/submit 